\title{
Evaluating expert advice in forecasting: Users' reactions to presumed vs. experienced credibility
}

\author{
Dilek Önkal ${ }^{\mathrm{a}, *}$, M. Sinan Gönül ${ }^{\mathrm{b}}$, Paul Goodwinn ${ }^{\mathrm{c}}$, Mary Thomson ${ }^{\mathrm{d}}$, Esra Öz ${ }^{\mathrm{a}}$ \\ a Bilkent University, Faculty of Business Administration, 06800 Ankara, Turkey \\ b Department of Business Administration, Middle East Technical University, 06800 Çankaya, Ankara, Turkey \\ c School of Management, University of Bath, Bath BA2 7AY, United Kingdom \\ ${ }^{\mathrm{d}}$ Newcastle Business School, Northumbria University, United Kingdom
}

\section{A R T I C L E I N F O}

\section{Keywords:}

Source credibility

Presumed credibility

Experienced credibility

Advice

Forecasting

Information use

\begin{abstract}
A B S T R A C T
In expert knowledge elicitation (EKE) for forecasting, the perceived credibility of an expert is likely to affect the weighting attached to their advice. Four experiments have investigated the extent to which the implicit weighting depends on the advisor's experienced (reflecting the accuracy of their past forecasts), or presumed (based on their status) credibility. Compared to a control group, advice from a source with a high experienced credibility received a greater weighting, but having a low level of experienced credibility did not reduce the weighting. In contrast, a high presumed credibility did not increase the weighting relative to a control group, while a low presumed credibility decreased it. When there were opportunities for the two types of credibility to interact, a high experienced credibility tended to eclipse the presumed credibility if the advisees were non-experts. However, when the advisees were professionals, both the presumed and experienced credibility of the advisor were influential in determining the weight attached to the advice. (C) 2016 International Institute of Forecasters. Published by Elsevier B.V. All rights reserved.
\end{abstract}

\section{Introduction}

The incorporation of experts' knowledge and judgments into forecasting processes poses a number of challenges, many of which are known to researchers who are seeking to improve expert knowledge elicitation (EKE) methods (e.g., Aspinall, 2010; Bolger \& Rowe, 2014, 2015; Budnitz et al., 1995; Cooke, 1991; Goodwin \& Wright, 2014; Meyer \& Booker, 1991; Morgan, 2014 and Morgan \& Henrion, 1990). One of these challenges is the need to assess the extent to which credence should be attached to an expert's forecasts. Concerns like this are relevant to the stages of EKE that involve the selection of experts, and

\footnotetext{
* Corresponding author.

E-mail address: onkal@bilkent.edu.tr (D. Önkal).
}

to the subsequent aggregation of their judgments when multiple experts are available. For example, either implicit or explicit differential weights may be attached to individual experts' judgments, depending on assessments of the probable accuracy of their forecasts. Errors made at either the selection or aggregation stages have the potential to harm the forecast accuracy. This raises the question of what determines the level of credibility that is associated with an expert's forecast.

This paper investigates the extent to which two attributes of experts - their track record of accuracy and their apparent status - influence the credibility of their forecasts. It does so by measuring how much either nonexperts or other experts revise their own forecasts after they have received an advisor's forecasts. Specifically, we investigate the influences of two types of credibility: the expert's track record as recalled by advisees (which 
we term 'experienced credibility') and the expert's status (which we term 'presumed credibility'). Our paper complements the work of Sah, Moore, and MacCoun (2013), who looked at the extent to which an advisor's track record and their confidence in their advice influenced opinion revision. The issues of presumed status and track records are also important because, as Armstrong suggested in his "seer sucker" theory, people are often motivated to pay large sums for forecasts elicited from people labeled 'experts', even when their forecasting accuracy is poor (Armstrong, 1980).

\section{Relevant literature}

Judgmental forecasts provided by experts are often used to inform people who are forming their own opinions of how the future will unfold (Gönül, Önkal, \& Lawrence, 2006). The domain of stock price forecasting is a prime example, being a field where a multi-billion dollar industry exists, comprising both forecast providers and forecast users. This field contains a great deal of uncertainty, and choosing a relatively inaccurate advisor can have serious repercussions, particularly for investments such as retirement savings. Accordingly, the credibility of the source of advice is likely to be of paramount importance; but how does source credibility influence a user's assessment of possible future stock prices? Do experienced and presumed credibility impinge on these assessments to different degrees, and what happens when these determinants yield conflicting indications of credibility?

Source credibility is an area of active research in many disciplines, including psychology, business, marketing, finance, risk communication, and information and health sciences (e.g., Berry \& Shields, 2014; Chen \& Tan, 2013; Gönül, Önkal, \& Goodwin, 2009; Sah et al., 2013; Willemsen, Neijens, \& Bronner, 2012 and Xie, Miao, Kuo, \& Lee, 2011). Expertise is argued to constitute a critical dimension of source credibility (e.g., Kelman \& Hovland, 1953). In fact, users have been shown to prefer 'expert forecasts' over 'computer-generated forecasts,' even when they had no information about either the experts or the statistical models generating these (actually identical) predictions (Önkal, Goodwin, Thomson, Gönül, \& Pollock, 2009).

In most situations, the greater the perceived expertise of the source of advice, the more persuasive the advice will be (Hovland \& Weiss, 1951; Johnson \& Izzett, 1969; Kelman \& Hovland, 1953; Lirtzman \& Shuv-Ami, 1986; McKnight \& Kacmar, 2007; Pornpitakpan, 2004; Tormala \& Clarkson, 2007). Furthermore, sources with high credibility have been found to be more persuasive than those with low credibility (e.g., Rhine \& Severance, 1970), although there have been contrary findings (e.g., Dholakia, 1986 and Dholakia \& Strenthal, 1977).

The suggested link between the credibility of a source of advice and the resultant change in an advisee's attitudes and judgments is also acknowledged by research on advice-taking (e.g. Bonaccio \& Dalal, 2006; Sah et al., 2013; See, Morrison, Rothman, \& Soll, 2011 and Yaniv, 2004). Van Swol and Sniezek (2005) investigated five factors that may affect the acceptance of advice: advisor confidence, advisor accuracy, the advisee's trust in the advisor, the advisee's prior relationship with the advisor, and the advisee's power to pay for the advisor's recommendations. Of these five factors, advisor confidence was found to have the most significant impact. An advisor's recommendations are more likely to be accepted if he/she has confidence in them. However, if feedback on advisor accuracy is also available, that cue will dominate, so that confident but inaccurate advisors will be perceived to be less credible (Sah et al., 2013).

Surprisingly little research has focused on the different forms of credibility and the potential interactions between them. One form is presumed credibility (Bonaccio \& Dalal, 2010; Harvey \& Fischer, 1997; Harvey, Harries, \& Fischer, 2000; Soll \& Larrick, 2009; Tseng \& Fogg, 1999), which is based on stereotypes and assumptions about the source of the advice. For instance, we may assume that a financial advisor will understand more about stocks and shares than, say, a taxi driver. Experienced credibility, on the other hand, is based on direct experience of the advisor, and results from interactions with them over time (Lim \& O'Connor, 1995; Soll \& Mannes, 2011; Tseng \& Fogg, 1999). For example, financial advisors who have proved to be highly proficient in the past should eventually attain high credibility in the minds of their clients.

Previous studies that have investigated advisor credibility have involved general judgment tasks such as quizzes on computer knowledge (e.g., Sniezek \& Van Swol, 2001 and Van Swol \& Sniezek, 2005), movie reviews (e.g., Van Swol, 2011), historical events/almanac items (e.g., Yaniv, 2004 and Yaniv \& Kleinberger, 2000), estimating alumni salaries (e.g., Bonaccio \& Dalal, 2010 and Soll \& Larrick, 2009), predicting the outcomes of sports events (e.g., Soll \& Mannes, 2011), and even estimating people's weights from photographs (e.g., Sah et al., 2013).

To add to this literature, we examine the specific influences of presumed and experienced credibility, both separately and jointly, on advisees - who may be either non-expert or expert - who are faced with the task of forecasting stock market prices. Two experiments were used to investigate the effects of high and low presumed and experienced credibility, separately, on the extent to which forecasting advice is influential. Our third and fourth experiments then investigated the effects of their interactions on non-experts and professionals, respectively. For example, how influential is advice when it is associated with high presumed but low experienced credibility? The influence of the advisor was measured by the extent to which people changed their initial forecasts in the light of the advice. The next sections describe the designs and results of these studies. This is followed by an overall discussion which considers the implications of the findings and provides suggestions for future research.

\section{Experiment 1-experienced credibility}

Some researchers have argued that experienced credibility is the most complex and reliable way of making credibility judgments (Fogg, 1999; Tseng \& Fogg, 1999; Wathern \& Burknell, 2002), and indeed, there is considerable evidence that the accuracy of prior stock price forecasts is a key element of provider credibility (e.g., Hirst, Koonce, \& Miller, 1999 and Lev \& Penman, 1990). However, 
of necessity, experienced credibility can only be based on a sample of the source's forecasts, and, in stock market forecasting, it is possible for a short run of highly accurate forecasts, achieved through luck rather than skill, to lead to an inflated perception of the source's credibility (Taleb, 2004). Thus, a high experienced credibility is likely to be associated with a record of a high accuracy over the forecasts in the sample. However, in the evaluation of the source's credibility, recent forecast errors may be overemphasized at the expense of the general performance. Nevertheless, we arrive at the following hypothesis.

H1: Advice from a source with a high experienced credibility will have more influence on user adjustments than advice from a source with a low experienced credibility, which, in turn, will have more influence than advice from a source where the user has no such accuracy experience.

Details of the experiment that we designed to test this hypothesis are given below.

\subsection{Participants}

The participants were 107 undergraduate business administration students who were taking a business forecasting course at Bilkent University. ${ }^{1}$ Participation led to extra credit points; no monetary incentives were given.

\subsection{Design and procedure}

Specially designed software based on the VBA (Visual Basic for Applications) platform was used to administer the experiment. The software presented the participants with time series plots for the weekly closing prices of 25 stocks. These stock prices belonged to real firms, and were drawn from the ISE50 (Istanbul Stock Exchange) index, all from the same time periods. Each time series plot displayed 30 weeks of past data. The participants were informed that these were real stock price series, but the stock names were undisclosed and the time periods concealed in order to prevent framing and extra information effects. The order that the time series were presented to the participants was random.

The initial 12 stocks were used for building experience. For these series, in addition to stock price data, the participants were also provided with forecasting advice in the form of a point forecast and a $90 \%$ prediction interval for the price of the stock in the 31st week, together with the actual observed price. During this stage, the participants were only required to examine the time series graph, with the provided advice and the realized outcomes (all plotted on the one graph), so that they could build their experience about the accuracy, and hence, the experienced credibility, of the forecasting source. A sample screenshot for this phase is attached in Appendix A. There were three experimental conditions, based on the nature of the forecasting advice:

\footnotetext{
1 The various experiments reported in current study were conducted with different participants. All three groups had similar gender breakdowns (with $45 \%-52 \%$ of participants being female) and age compositions (the mean age was 22, with a range of 21-23).
}

1. The high experienced credibility group $(n=38)$ : For the initial 12 experience-building series, the forecasting advice given to this group was highly accurate. The advice was generated statistically, and the error levels were set to have mean absolute percentage errors (MAPE) of $2.94 \%$ for the point forecasts and hit rates of $10 / 12$ (83.3\%) for the prediction intervals.

2. The low experienced credibility group $(n=34)$ : The forecasting advice observed over the initial 12 experiencebuilding series was relatively inaccurate. The error levels were set to have MAPEs of $14.94 \%$ for the point forecasts and hit rates of $2 / 12$ (16.7\%) for the intervals.

3. The control group-no forecasting advice $(n=35)$ : The participants in this group did not receive any forecast advice during the initial phase (to avoid building any experience about the accuracy of the forecasting source). Thus, for the initial series, these participants were only shown the time series plots and the realized outcomes.

Once these 12 series had been displayed, a single window appeared (for the high and low experienced credibility groups only, not for the control group) and summarized the overall performances of the forecasting advice provided. Next, a practice time series was provided, to help the participants to get used to the interface. Following the practice series, 12 new stock price series were displayed. In this phase, for each of the 12 stocks:

i. The participants were asked to make a one-periodahead point forecast for the stock's closing price in week 31 , with a $90 \%$ prediction interval. These forecasts constituted the participants' initial predictions.

ii. They were then provided with forecasting advice, in the form of a point forecast and a $90 \%$ prediction interval. Note that all groups received exactly the same advice in this second phase. The accuracy level of the advice provided was set approximately midway between the high and low credibility levels (MAPEs of $9.10 \%$ for the point forecasts and hit rates of $50 \%$ for the interval forecasts). The participants were not aware of this, as they were never shown the realized outcomes from this phase.

iii. The participants were then requested to examine the forecasts provided, and to revise their initial forecasts if they considered this necessary. A sample screenshot from this phase is provided in Appendix A.

Before each experimental session, the instructions were discussed and detailed examples of the use of the software were provided. At the end, each participant was presented with a wrap-up questionnaire.

\subsection{Performance measures}

For each of the experiments here, two sets of results are reported. The first set reports the judgmental adjustments applied to the initial forecasts (both point and interval predictions) for each source credibility condition. The second set reports the findings on advice utilization.

\subsubsection{Judgmental adjustments of the initial forecasts}

One would expect a direct link between the influence of the forecasting source and the judgmental adjustments 
Table 1

Judgmental adjustment measures.

\begin{tabular}{|c|c|c|c|}
\hline & Frequency of adjustments & Size/magnitude of adjustments & \\
\hline Point forecasts & $\%$ of initial point forecasts adjusted & $\begin{array}{l}\text { AAP absolute adjustment in point } \\
\text { forecasts }\end{array}$ & $\begin{array}{l}\text { APAP absolute \% adjustment in point } \\
\text { forecasts }\end{array}$ \\
\hline Interval forecasts & $\%$ of initial interval forecasts adjusted & $\begin{array}{l}\text { SAA sum of absolute adjustments on } \\
\text { interval bounds }\end{array}$ & $\begin{array}{l}\text { APAI absolute \% adjustment in interval } \\
\text { forecast width }\end{array}$ \\
\hline
\end{tabular}

applied by the participants to their initial forecasts. If the advice coming from the forecasting source is perceived to be persuasive, then, in general, the adjustments to the initial predictions would be expected to be larger and more frequent for a more credible source.

The frequency of adjustment was measured by the percentage of the initial point and interval forecasts that were modified. An alteration to at least one of the upper or lower bounds of an interval forecast was counted as an adjustment. The sizes of these adjustments were assessed by using different measures for point and interval predictions. The measures used are summarized in Table 1.

The AAP and SAA measures were used by Goodwin, Gönül, and Önkal (2013). The APAP and APAI measures have been used in many previous studies (e.g., Gönül et al., 2006 and Önkal, Gönül, \& Lawrence, 2008), and were chosen to complement the AAP and SAA scores by providing scale-free measurements. All of these scores receive the typical value of ' 0 ' when the initial forecasts remain unadjusted. The formulae used to calculate these four measures are as follows:

$A A P=\mid$ adjusted point forecast - initial point forecast $\mid$

$S A A=\mid$ adjusted upper bound - initial upper bound $\mid$

$+\mid$ adjusted lower bound - initial lower bound $\mid$

$A P A P=\frac{\mid \text { adjusted point forecast }- \text { initial point forecast } \mid}{\text { initial point forecast }} \times 100$

$A P A I=\frac{\mid \text { adjusted interval width }- \text { initial interval width } \mid}{\text { initial interval width }} \times 100$.

\subsubsection{Advice utilization}

Three scores for measuring the adoption of advice have been suggested in the literature (Bonaccio \& Dalal, 2006; Harvey \& Fischer, 1997; Yaniv, 2004; Yaniv \& Kleinberger, 2000). All of these scores measure the extent to which advice is used by considering how the final point forecast is situated relative to the initial point forecast and the point forecast provided.

The three scores are as follows.

(i) Advice-shift

$$
\begin{aligned}
& \text { Advice shift } \\
& =\frac{\text { adjusted point forecast }- \text { initial point forecast }}{\text { provided point forecast }- \text { initial point forecast }} .
\end{aligned}
$$

In its standard form, this score, which was proposed by Harvey and Fischer (1997), has a value between 0 and 1 . A score of 0 represents perfect discounting of the advice (i.e., the adjusted point forecast is equal to the initial point forecast, meaning that the advice provided has no impact on the forecaster), while a score of 1 represents perfect utilization (i.e., the adjusted point forecast is equal to the point forecast provided). A score that is smaller than 0.5 indicates that the final forecast is closer to the initial forecast, while a score over 0.5 indicates that it is closer to the prediction provided. One disadvantage of this measure is the implicit assumption that the adjusted forecast should reside somewhere between the initial forecast and the advice provided. Negative values or scores greater than one are often considered "extraordinary" cases (Bonaccio \& Dalal, 2006).

(ii) Weight-of-advice (WoA)

$$
\begin{aligned}
& \text { WoA } \\
& =\frac{\mid \text { adjusted point forecast }- \text { initial point forecast } \mid}{\mid \text { provided point forecast }- \text { initial point forecast } \mid} .
\end{aligned}
$$

The WoA measure was developed by Yaniv (2004), and is, in fact, simply the advice shift score with absolute values of the numerator and denominator. The possible scores and their interpretations are very similar to those of the former measure, with the exception that WoA can never yield negative values. Thus, extraordinary cases occur only when the score is greater than one.

(iii) Weight-of-own estimate (WoE)

$$
\begin{aligned}
& \text { WoE } \\
& =\frac{\mid \text { provided point forecast }- \text { adjusted point forecast } \mid}{\mid \text { provided point forecast }- \text { initial point forecast } \mid} .
\end{aligned}
$$

Yaniv and Kleinberger (2000) suggested this score for measuring advice discounting. Again, in its standard form, this measure yields a value between 0 and 1 , where 1 represents perfect discounting and 0 perfect utilization of the advice. Extraordinary cases are represented by scores greater than one. Note that none of these scores are defined for cases where the initial and provided point predictions are the same.

\subsection{Results: judgmental adjustments of the initial forecasts}

Table 2 exhibits the frequency and mean size of the judgmental adjustments applied to the initial point and interval predictions for each source condition. The $F$ and $p$ values in Table 2 relate to one-way ANOVA analyses which take into account the repeated measures design of the experiment. They reveal that there are significant differences among the three source conditions across all measures for both point and interval forecasts. For point predictions, groups that experienced any type of credibility adjusted 
Table 2

Judgmental adjustments on initial forecasts in Experiment 1.

\begin{tabular}{|c|c|c|c|}
\hline Point forecasts & $\%$ of initial point forecasts adjusted & AAP & APAP \\
\hline Experienced credibility: high & $\begin{array}{l}80.92 \% \\
(456)\end{array}$ & $\begin{array}{l}0.35 \\
(456)\end{array}$ & $\begin{array}{l}4.37 \% \\
(456)\end{array}$ \\
\hline Experienced credibility: low & $\begin{array}{l}79.90 \% \\
(408)\end{array}$ & $\begin{array}{l}0.23 \\
(408)\end{array}$ & $\begin{array}{l}2.91 \% \\
(408)\end{array}$ \\
\hline \multirow[t]{2}{*}{ Control group } & $\begin{array}{l}57.62 \% \\
(420)\end{array}$ & $\begin{array}{l}0.22 \\
(420)\end{array}$ & $\begin{array}{l}2.76 \% \\
(420)\end{array}$ \\
\hline & $\begin{array}{l}F_{2,104}=6.82, p=0.002 \\
\eta_{p}^{2}=0.12\end{array}$ & $\begin{array}{l}F_{2,104}=5.75, p=0.004 \\
\eta_{p}^{2}=0.10\end{array}$ & $\begin{array}{l}F_{2,104}=5.47, p=0.006 \\
\eta_{p}^{2}=0.10\end{array}$ \\
\hline Interval forecasts & $\%$ of initial interval forecasts adjusted & SAA & APAI \\
\hline Experienced credibility: high & $\begin{array}{l}86.84 \% \\
(456)\end{array}$ & $\begin{array}{l}0.72 \\
(456)\end{array}$ & $\begin{array}{l}25.30 \% \\
(456)\end{array}$ \\
\hline Experienced credibility: low & $\begin{array}{l}85.54 \% \\
(408)\end{array}$ & $\begin{array}{l}0.54 \\
(408)\end{array}$ & $\begin{array}{l}19.24 \% \\
(408)\end{array}$ \\
\hline \multirow[t]{2}{*}{ Control group } & $\begin{array}{l}66.67 \% \\
(420)\end{array}$ & $\begin{array}{l}0.47 \\
(420)\end{array}$ & $\begin{array}{l}15.53 \% \\
(420)\end{array}$ \\
\hline & $\begin{array}{l}F_{2,104}=5.51, p=0.005 \\
\eta_{p}^{2}=0.10\end{array}$ & $\begin{array}{l}F_{2,104}=4.39, p=0.015 \\
\eta_{p}^{2}=0.08\end{array}$ & $\begin{array}{l}F_{2,104}=6.98, p=0.001 \\
\eta_{p}^{2}=0.12\end{array}$ \\
\hline
\end{tabular}

Note: the numbers in parentheses indicate the numbers of observations in each category.

significantly more often than participants in the control group, who received no information from which to build any source-related experience (high experienced credibility vs. control group: $F_{1,71}=10.62, p=0.002, \eta_{p}^{2}=0.13$; low experienced credibility vs. control group: $F_{1,67}=8.12$, $p=0.006, \eta_{p}^{2}=0.11$; Tukey's HSD-high experienced credibility vs. control group: $p=0.004$; low experienced credibility vs. control group: $p=0.007$ ). However, the adjustment frequencies of the high and low credibility groups were similar $(p>0.1)$.

In terms of the sizes of adjustments, the group experiencing high credibility applied larger adjustments to the initial forecasts than either the low experienced credibility group (Tukey's HSD: $p=0.021$ for AAP; $p=0.023$ for APAP) or the control group (Tukey's HSD: $p=0.007$ for AAP; $p=0.01$ for APAP). On average, participants who experienced low credibility made adjustments of similar sizes to those in the control group $(p>0.1$ for both AAP and APAP).

Similar findings apply to the interval predictions. The high and low experienced credibility groups had similar adjustment frequencies (high vs. low: n.s., $p>0.1$ ), but these groups adjusted significantly more often than the control group (Tukey's HSD: high vs. control: $p=0.009$; low vs. control: $p=0.020$ ). The SAA and APAI scores indicate that the high experienced credibility group modified their initial intervals by larger amounts than either the control group (Tukey's HSD: $p=0.014$ for SAA; $p=0.001$ for APAI) or the low credibility group. However, the difference between the high and low experienced credibility groups was not as pronounced as in the case of point predictions (Tukey's HSD: $p=0.1$ for SAA; $p=0.06$ for APAI). When the mean interval adjustments of the low experienced credibility group were compared with those of the control group, they were similar in size $(p>0.2$ for both SAA and APAI).

\subsection{Results: advice utilization}

The advice utilization scores were calculated for all of the initial and adjusted forecast pairs except for the rare (9 out of 1284) cases where the initial prediction was exactly equal to the forecasting advice provided. In three of these cases, the initial predictions also equaled the final forecasts, so they were assigned perfect discounting scores ( 0 for advice-shift and WoA, 1 for WoE). The remaining six pairs were omitted from the subsequent calculations. $86.76 \%$ of all initial and adjusted forecast pairs had scores between 0 and 1 on the WoA and WoE measures (1114 pairs out of 1284). The remaining $12.54 \%$ of pairs were classified as "extraordinary" instances of using external advice. Table 3 shows the scores for advice-shift, WoA and $\mathrm{WoE}$ for each source condition on the aggregate data (i.e., with the ordinary and extraordinary cases combined).

The results indicate that the differences in advice utilization across the credibility groups were significant. The advice-shift scores suggest that the high experienced credibility group shifted their initial forecasts closer to the predictions provided than either the low credibility group (Tukey's HSD: $p=0.046$ ) or the control group (Tukey's HSD: $p=0.033$ ). However, the group that were given advice from the low experienced credibility source did not appear to use the advice any differently to the group who were not given any chance to acquire experience about the source $(p>0.2)$.

Overall, these results suggest that, compared to situations where there is no means of assessing a source's probable accuracy, any experience of a source's accuracy is likely to increase the frequency of adjustments by similar amounts, regardless of what this accuracy is. When equipped with no information with which to determine the credibility of the source, individuals were more reluctant to modify their original forecasts.

However, it could be argued that influence can be measured more finely by scores that reflect the sizes of 
Table 3

Mean advice utilization scores for both ordinary and extraordinary cases in Experiment 1.

\begin{tabular}{|c|c|c|c|}
\hline & Advice-shift & WoA & WoE \\
\hline Experienced credibility: high & $\begin{array}{l}0.42 \\
(455)\end{array}$ & $\begin{array}{l}0.44 \\
(455)\end{array}$ & $\begin{array}{l}0.62 \\
(455)\end{array}$ \\
\hline Experienced credibility: low & $\begin{array}{l}0.18 \\
(406)\end{array}$ & $\begin{array}{l}0.42 \\
(406)\end{array}$ & $\begin{array}{l}0.89 \\
(406)\end{array}$ \\
\hline \multirow[t]{2}{*}{ Control group } & $\begin{array}{l}0.18 \\
(417)\end{array}$ & $\begin{array}{l}0.39 \\
(417)\end{array}$ & $\begin{array}{l}0.86 \\
(417)\end{array}$ \\
\hline & $\begin{array}{l}F_{2,104}=4.65, p=0.012 \\
\eta_{p}^{2}=0.08\end{array}$ & N.S. $p>0.1$ & $\begin{array}{l}F_{2,104}=3.46, p=0.035 \\
\eta_{p}^{2}=0.06\end{array}$ \\
\hline
\end{tabular}

Note: the numbers in parentheses indicate the numbers of observations in each category.

the adjustments and the degree of advice utilization. These measures indicate that a high experienced credibility leads to a greater influence than a low experienced credibility, which is consistent with $\mathrm{H} 1$. Also, the source has more influence if a higher accuracy of the forecasting source is experienced than if people have no experience of the source's accuracy. This also provides support for H1. In contrast, a low experienced credibility did not lead to the advice having less influence than that of the control group, so there was no support for this component of H1. Thus, while people in the low experienced credibility condition adjusted more frequently than those in the control group, the average sizes of their adjustments were similar.

The wrap-up questionnaire data provide further insights into these results. Rating their performance perceptions for the advice provided (on a seven-point scale, with $1=$ "very poor" and $7=$ "excellent"), participants gave mean scores of $4.53,3.18$ and 3.74 for the high experienced credibility, low experienced credibility and control groups, respectively. The differences among these ratings are significant $\left(F_{2,104}=11.28, p<0.001, \eta_{p}^{2}=0.18\right)$, and pairwise comparisons indicate that the differences between high and low (Tukey's HSD: $p<0.001$ ) and high and control (Tukey's HSD: $p=0.019$ ) are significant, while the difference between 'low' and 'control' is not statistically significant (Tukey's HSD: $p>0.1$ ). These findings provide further partial support for H1, but again, its third component is not supported.

\section{Experiment 2-presumed credibility}

The stock market is a domain in which financial advisors earn a living, at least in part, by encouraging a presumption of expertise, regardless of their actual track record of success. Kahneman (2011) has referred to the 'illusion of financial skill', and the fact that people are often prepared to pay for advice only on the basis of presumed credibility suggests that it is influential (Armstrong, 1980). As Gardner (2011) points out: "As social animals we are exquisitely sensitive to status", and, as such, the perceived quality of advice, and hence its influence, are likely to depend to some extent on the status of the source. According to expectation states theory, people judge one another on the basis of status characteristics, which, in turn, influence expectations about performance competency (for detailed reviews, see e.g., Berger, Fisek, Norman, \& Zelditch, 1977 and Correll \& Ridgeway, 2003). This leads to the following hypothesis:
H2 Advice from a source with a high presumed credibility will have more influence on user adjustments than advice from a source with a low presumed credibility, which, in turn, will have more influence than advice from an unattributed source.

Details of the experiment that we designed to test this hypothesis are given below.

\subsection{Participants}

The participants were 93 undergraduate business administration students who were taking a business forecasting course at Bilkent University. No monetary incentives were given, but participation in the study led to extra credit points.

\subsection{Design and procedure}

Since this experiment was designed to investigate the influence of the presumed credibility of a forecasting source, there were no experience-building series. After a single practice series to familiarize the participants with the software interface, participants were given time series plots for the weekly closing prices of 12 stocks (the same stocks as in the second phase of Experiment 1). As before, the participants were informed that these were real stock price series with undisclosed stock names and concealed time periods. There were three experimental conditions, depending on the nature of the forecasting advice:

1. The high presumed credibility group $(n=34)$ : For each series, the forecasting advice was presented with a label displaying the message: "Source of this forecast advice is a well-known financial analyst with extensive knowledge of stock price forecasting". This was designed to encourage the participants to attribute a high presumed credibility to the forecast source.

2. The low presumed credibility group $(n=31)$ : For each series, the forecasting advice was presented with a label displaying "Source of this forecast advice is a taxi driver", so as to foster a low presumed credibility of the source of the forecast advice. It is worth noting that it is very common in Turkey (where the experiment took place) for the taxi drivers to engage in conversations on the economy and financial markets; so the participants treated this as a frequently encountered and highly realistic situation. A sample screenshot from the practice series is provided in Appendix B.

3. The control group-no presumed credibility $(n=28)$ : The participants in this group received the forecasting 
Table 4

Judgmental adjustments to initial forecasts in Experiment 2.

\begin{tabular}{|c|c|c|c|}
\hline Point forecasts & $\%$ of initial point forecasts adjusted & AAP & APAP \\
\hline Presumed credibility: high & $\begin{array}{l}86.03 \% \\
(408)\end{array}$ & $\begin{array}{l}0.39 \\
(408)\end{array}$ & $\begin{array}{l}4.86 \% \\
(408)\end{array}$ \\
\hline Presumed credibility: low & $\begin{array}{l}72.04 \% \\
(372)\end{array}$ & $\begin{array}{l}0.22 \\
(372)\end{array}$ & $\begin{array}{l}2.75 \% \\
(372)\end{array}$ \\
\hline \multirow[t]{2}{*}{ Control group } & $\begin{array}{l}76.19 \% \\
(336)\end{array}$ & $\begin{array}{l}0.33 \\
(336)\end{array}$ & $\begin{array}{l}4.10 \% \\
(336)\end{array}$ \\
\hline & N.S. $p=0.08$ & $\begin{array}{l}F_{2,90}=5.64, p=0.005 \\
\eta_{p}^{2}=0.11\end{array}$ & $\begin{array}{l}F_{2,90}=5.66, p=0.005 \\
\eta_{p}^{2}=0.11\end{array}$ \\
\hline Interval forecasts & $\%$ of initial interval forecasts adjusted & SAA & APAI \\
\hline Presumed credibility: high & $\begin{array}{l}91.18 \% \\
(408)\end{array}$ & $\begin{array}{l}0.83 \\
(408)\end{array}$ & $\begin{array}{l}31.11 \% \\
(408)\end{array}$ \\
\hline Presumed credibility: low & $\begin{array}{l}77.42 \% \\
(372)\end{array}$ & $\begin{array}{l}0.45 \\
(372)\end{array}$ & $\begin{array}{l}17.26 \% \\
(372)\end{array}$ \\
\hline \multirow[t]{2}{*}{ Control group } & $\begin{array}{l}83.93 \% \\
(336)\end{array}$ & $\begin{array}{l}0.71 \\
(336)\end{array}$ & $\begin{array}{l}24.39 \% \\
(336)\end{array}$ \\
\hline & N.S. $p=0.09$ & $\begin{array}{l}F_{2,90}=8.06, p=0.001 \\
\eta_{p}^{2}=0.15\end{array}$ & $\begin{array}{l}F_{2,90}=7.97, p=0.001 \\
\eta_{p}^{2}=0.15\end{array}$ \\
\hline
\end{tabular}

Note: the numbers in parentheses indicate the numbers of observations in each category.

advice without any labels, so that no credibility about the source could be presumed.

For each stock, the task of the participants was the same as in Experiment 1. Participants in all treatments received identical advice, and a wrap-up questionnaire was presented at the end of the experiment.

\subsection{Results: judgmental adjustments of initial forecasts}

The frequency and mean sizes of judgmental adjustments for the different presumed credibility conditions are displayed in Table 4.

Table 4 shows that there are significant differences between the three source conditions in the size of adjustments. However, while a similar pattern exists for the adjustment frequency, the differences among the groups were not strong enough to reach statistical significance.

In terms of pairwise comparisons, for both point and interval forecasts, the group who believed that they had received forecasting advice from a financial expert made larger adjustments to their initial predictions than the group who believed that their advice source was a taxi driver (Tukey's HSD: $p=0.004$ for AAP; $p=0.003$ for APAP; $p>0.001$ for SAA and $p>0.001$ for APAI). When the adjustments of the high presumed credibility group were compared with those of the control group who did not receive any information about the source, the differences in both frequency and size were all non-significant (all $p>0.05$ ). The low presumed credibility group, who believed that their forecasting advice was coming from a taxi driver, adjusted their initial forecasts less than the control group. However, this difference was generally small and attained statistical significance only in the case of SAA (Tukey's HSD: $p=0.029$ for SAA). Thus, there was mixed support for $\mathrm{H} 2$.

\subsection{Results: advice utilization}

As in Experiment 1, the advice utilization scores were calculated for all initial and adjusted forecast pairs except for the cases where the initial and provided forecasts were identical (this occurred in only six out of 1116 cases). Of these six pairs, three also had the initial predictions equal to the final forecasts, so perfect advice discounting scores (" 0 " for advice-shift and WoA, " 1 " for WoE) were assigned. The remaining three pairs were omitted from the subsequent calculations.

"Ordinary" cases of advice utilization were evident for $88.35 \%$ of all initial and adjusted forecast pairs. The remaining pairs constituted the "extraordinary" instances. Table 5 provides advice-shift, WoA and WoE results for each source condition on the aggregate data (ordinary and extraordinary cases combined).

An inspection of Table 5 reveals that there are significant differences in advice utilization among the three presumed credibility groups. All of the scores show that the group who believed that they had received advice from a financial expert had much higher utilization rates than the group who were told that they have received advice from a taxi driver $\left(F_{1,63}=13.48, p>0.001, \eta_{p}^{2}=0.18\right.$ for advice-shift, $F_{1,63}=13.24, p=0.001, \eta_{p}^{2}=0.17$ for WoA and $F_{1,63}=13.06, p=0.001, \eta_{p}^{2}=0.17$ for WoE; Tukey's HSD: $p=0.002$ for advice-shift, $p=0.002$ for WoA and $p=0.002$ for WoE). This provides further support for $\mathrm{H} 2$. However, there was no significant difference between the advice utilization levels of the high presumed credibility group and the control group on any of the scores $(p>0.1$ for advice-shift, WoA and WoE), so again the second component of $\mathrm{H} 2$ was not supported. As before, advice received from an anonymous source (as was the case with the control group) enjoyed slightly (but not significantly) higher utilization rates than advice received from a low credibility source (Tukey's HSD: $p=0.07$ for advice-shift, $p=0.07$ for WoA and $p<0.1$ for WoE).

Further insights into these results can be gathered from the wrap-up questionnaire data. When the participants were asked for their perception of the advisor's performance (via a seven-point scale, with $1=$ "very poor" 
Table 5

Mean advice utilization scores for both ordinary and extraordinary cases in Experiment 2. (Note: the numbers in parentheses indicate the numbers of observations in each category.)

\begin{tabular}{llll}
\hline & Advice-shift & WoA & WoE \\
\hline Presumed credibility: high & 0.47 & 0.50 \\
& $(407)$ & $(407)$ & 0.59 \\
Presumed credibility: low & 0.24 & 0.27 & $(407)$ \\
Control group & $(371)$ & 0.78 \\
& 0.40 & 0.43 & $(335)$ \\
$(371)$ & $F_{2,90}=6.13, p=0.003$ & $\eta_{p}^{2}=0.12 \quad$
\end{tabular}

Note: the numbers in parentheses indicate the numbers of observations in each category.

and $7=$ "excellent"), their mean ratings were 4.65 , 3.19 and 4.18 for the high and low presumed credibility groups and the control group, respectively. A one-way ANOVA revealed that these scores were significantly different $\left(F_{2,90}=9.87, p>0.001, \eta_{p}^{2}=0.18\right)$. The difference between the high and low presumed credibility groups was significant (Tukey's HSD: $p>0.001$ ), as was the difference between the low presumed credibility group and the control group (Tukey's HSD: $p=0.016$ ). However, the difference between the high credibility group and the control group was not significant (Tukey's HSD: $p>0.3$ ). These findings are consistent with the results of the experiment itself, and provide partial support for $\mathrm{H} 2$.

Overall, these analyses reveal that when the presumed credibility of a forecasting source is high, the advice received from that source is more influential than that received from a source with a low presumed credibility. However, there was no evidence that a high presumed credibility led to a greater influence than advice from an unattributed source. This finding could be an indication of truth bias (Levine \& McCornack, 1991; Levine, Park, \& McCornack, 1999), which refers to the tendency to presume that messages received are true rather than untrue, irrespective of the actual accuracy of the information conveyed. The presumption of truth is reduced when there is a reason to infer that the message is untrue.

\section{Experiment 3-experienced and presumed credibility}

In many circumstances, people will base their assessment of an expert's credibility on both their experience of the expert's accuracy (i.e., advice source) and the presumed credibility of the source. This raises the question of how the two forms of credibility interact, and, in particular, what happens when they give conflicting indications.

The literature suggests five possible models of the relationship between a satisfaction with advice and presumed and experienced credibility. Armstrong's (1980) 'seer sucker' theory suggests a 'presumption-only’ model, where people will be influenced by the advice of those who they presume to have the status of experts, irrespective of their track record. The predictions of this model are depicted in Fig. 1(a) (the lines are intended to be coincidental). This dominance of presumption may arise because people are not motivated to examine advisors' track records.

At the other extreme is an 'experience-only' model, where the presumed credibility has no influence when experience of the advice is available. There is some support for this model from research in other domains. For example, Brown, Venkatesh, Kuruzovich, and Massey (2008) found that expectations had no influence on users' satisfaction with the ease-of-use of information systems; satisfaction depended only upon experience of the system. Similarly, Irving and Meyer (1994) found that experiences rather than expectations determined levels of job satisfaction. Brown et al. suggested that the predominance of experience may be a recency effect, because experience always follows expectations. Indeed, very recent experience appears to be particularly influential for forecasting, and a good reputation can be lost easily after very few inaccurate forecasts (Yaniv \& Kleinberger, 2000). Fig. 1(b) indicates the predictions of the experience-only model.

If presumption and experience of advice are both influential separately, then the experience + presumption model in Fig. 1(c) may apply. However, there is evidence that satisfaction with the advice will depend upon whether the presumption is confirmed or contradicted by the experience. Discrepancies between expectations and experiences have been examined particularly in relation to satisfaction with products (e.g., Anderson, 1973) and information systems (Bhattacherjee, 2001). Research in the two areas has produced similar findings. For example, when experience is consistent with expectations, user satisfaction with an information system is increased. This occurs even when expectations are low, although the satisfaction levels are lower in these circumstances than when high expectations are confirmed (Venkatesh \& Goyal, 2010).

Brown et al. (2008) suggest two possible models of the formation of satisfaction when such discrepancies arise. In the 'disconfirmation model', better-than-expected experiences lead to a positive influence on satisfaction, because there is a 'positive surprise' effect, while worsethan-expected experiences lead to a reduced satisfaction, because there is a 'disappointment effect'. This model is consistent with the 'met expectations hypothesis', which suggests that satisfaction depends on the difference between experiences and expectations (e.g., Porter \& Steers, 1973). The predictions of the 'disconfirmation' model in the context of forecasting advice are shown in Fig. 1(d). In this model, a high experienced credibility will always have more influence on the use of advice than a low experienced credibility, since the former will raise satisfaction if it is unexpected, while the latter will lower 


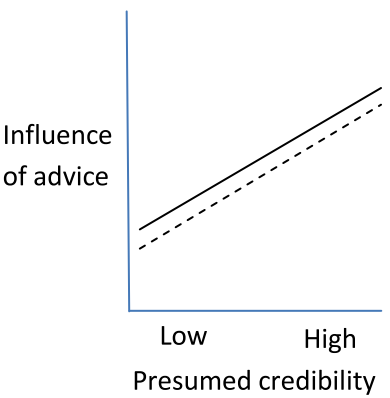

(a) Presumption-only.

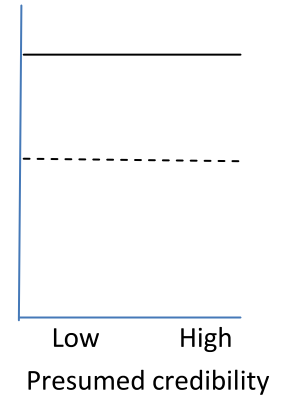

(b) Experience-only.

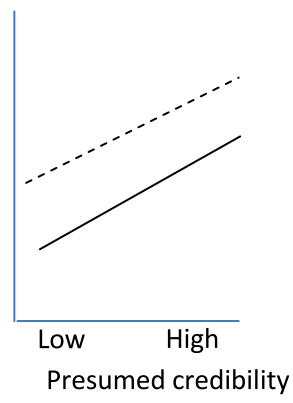

(c) Experience + presumption.

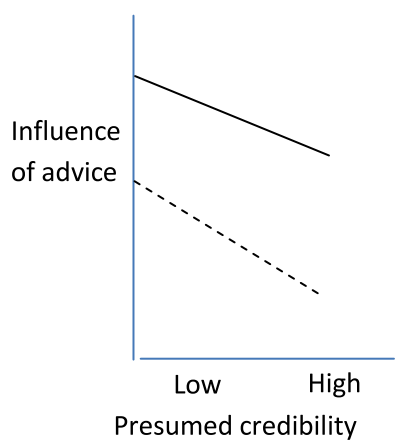

(d) Disconfirmation.

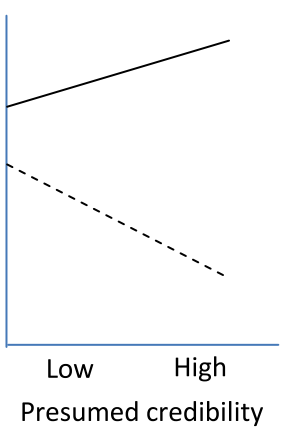

(e) Ideal-point.

= low experienced credibility = high experienced credibility

Fig. 1. Five models predicting the influence of expert advice.

it if it is unexpected. Given Venkatesh and Goyal's (2010) findings, the model also predicts that high presumed and experienced credibility will have more influence than low presumed and experienced credibility

However, while a 'positive surprise' may have a positive effect on variables such as job satisfaction, which are related directly to the happiness of an individual, the same may not be true in the case of forecasting advice. Here, a discrepancy between presumption and experience may lead to psychological discomfort or cognitive dissonance (Festinger, 1957), irrespective of whether the experience is better or worse than expected. In this case, an 'ideal point model' (Brown et al., 2008) may apply. This model assumes there is an ideal 'point' of experience where the differences between presumption and experience are at a minimum. People do not like to be wrong, and therefore, in contrast to the 'disconfirmation model', even a better-than-presumed experience will lead to a reduced satisfaction because the discomfort of a thwarted presumption exceeds the satisfaction of the positive surprise (Carlsmith \& Aronson, 1963; Oliver, 1977, 1980; Woodside \& Parrish, 1972). The predictions of the 'ideal point' model for the influence of forecasting advice are shown in Fig. 1(e). Here, the greatest influence on forecasters will be when both the presumed and experienced credibility are high, as there will be both a synergistic effect, with each form of credibility enhancing the influence of the other, and an absence of cognitive dissonance, because the advisees do not experience any psychological discomfort (Elliot \& Devine, 1994; Szajna \&
Scamell, 1993). While a better-than-presumed experience may partly mitigate the reduced satisfaction that arises from the discrepancy, an experience that is worse than presumed will not serve to reduce this discomfort. Thus, it will reduce the satisfaction even more. In a practical context, this reduction in satisfaction may result from annoyance that a person described as an 'expert' has exhibited a poor performance, with catastrophic effects for their credibility. This is reflected in the fact that the "low experienced credibility' line in Fig. 1(e) has the greater absolute slope. In this model, it is also possible for the lines to intersect, so that low presumed and experienced credibility could have more influence than low presumed, high experienced credibility. This seems unlikely, but would arise if there was a large amount of dissatisfaction from the discrepant experience.

\subsection{Participants}

The participants were 65 undergraduate business administration students who were taking a business forecasting course at Bilkent University. As with the previous studies, there were no monetary incentives, but participation led to extra credit points.

\subsection{Design and procedure}

The design and procedure for Experiment 3 represented a combination of those of the previous two studies. 


\begin{tabular}{|c|c|c|}
\hline & $\begin{array}{l}\text { High presumed credibility } \\
\text { "Source of this forecast advice is a } \\
\text { well-known financial analyst with } \\
\text { extensive knowledge of stock price } \\
\text { forecasting" }\end{array}$ & $\begin{array}{l}\text { Low presumed credibility } \\
\text { "Source of this forecast advice is a taxi } \\
\text { driver" }\end{array}$ \\
\hline $\begin{array}{l}\text { High experienced credibility } \\
\text { [Initial } 12 \text { experience-building series had a MAPE of } \\
2.94 \% \text { for the point forecasts and a hit rate of } 83 \% \text { for the } \\
\text { intervals] }\end{array}$ & $18(\mathrm{G} 1)$ & $16(\mathrm{G} 3)$ \\
\hline $\begin{array}{l}\text { Low experienced credibility } \\
\text { [Initial } 12 \text { experience-building series had a MAPE of } \\
14.94 \% \text { for the point forecasts and a hit rate of } 17 \% \text { for } \\
\text { the intervals] }\end{array}$ & $16(\mathrm{G} 2)$ & 15 (G4) \\
\hline
\end{tabular}

Note: the numbers in the cells indicate the numbers of participants, with group codes shown in parentheses.

As before, specifically tailored software was used to administer the experiment. The software presented time series plots for the weekly closing prices of 25 stocks (the same stocks that were used in Experiment 1), with the same initial 12 stocks being used as the experiencebuilding time series. Table 6 exhibits the four experimental conditions based on the experienced accuracy and the presumed credibility cues that were provided.

The procedure followed by the participants was the same as that in Experiment 1.

\subsection{Results: judgmental adjustments of initial forecasts}

Table 7 displays the frequency and mean size of the judgmental adjustments to the initial forecasts when both experienced and presumed credibility cues are present at the same time.

$2 \times 2$ factorial ANOVA analyses which take into account the repeated measures design of the experiment were run to investigate the factor effects and the significance of the differences. The $F$-test scores in Table 7 indicate that there exist significant differences among the four credibility groups for all six measures considered.

For point forecasts, the experienced credibility factor had a significant main effect on both the frequency $\left(F_{1,61}=\right.$ $\left.13.02, p=0.001, \eta_{p}^{2}=0.18\right)$ and size $\left(F_{1,61}=15.40, p<\right.$ $0.001, \eta_{p}^{2}=0.20$ for AAP; $F_{1,61}=14.32, p<0.001, \eta_{p}^{2}=$ 0.19 for APAP) of adjustments. Neither the main effect of the presumed credibility condition nor the interaction effect between experienced and presumed credibility were found to be significant (all $p>0.05$ ). Pairwise comparisons among the groups revealed that the high presumed and experienced credibility group made larger adjustments and adjusted more frequently than the groups experiencing low credibility (Tukey's HSD for G1 vs. G2: $p=$ 0.0043 for the percentage of point forecasts adjusted, $p=$ 0.0006 for AAP and $p=0.0008$ for APAP; Tukey's HSD for G1 vs. G4: $p=0.0073$ for the percentage of point forecasts adjusted, $p=0.0074$ for AAP and $p=0.0102$ for APAP). This may suggest that presumptions about the source do not have much influence when the forecasters have a chance to actually experience high credibility (Tukey's HSD for G1 vs. G3: $p>0.1$ for all measures). Thus, the results are consistent with an experience-only model. None of the other differences between the groups were strong enough to attain statistical significance (Tukey's HSD $p>0.1$ ).
Parallel findings were obtained for interval forecasts. For the percentage of initial interval forecasts adjusted and the SAA scores, the only significant factor was the main effect of experienced credibility $\left(F_{1,61}=8.95, p=\right.$ $0.004, \eta_{p}^{2}=0.13 ; F_{1,61}=13.63, p<0.001, \eta_{p}^{2}=$ 0.18 , respectively). The presumed credibility factor and the interaction effect between the two types of credibility were not found to have any impact on these two scores (all $p>0.1$ ). The largest and most frequent adjustments to the initial predictions were made when the forecasters experienced a high credibility about a source that was presumed to be highly credible (Tukey's HSD for G1 vs. G2: $p=0.0261$ for the percentage of point forecasts adjusted and $p=0.0016$ for SAA; Tukey's HSD for G1 vs. G4: $p=$ 0.0172 for the percentage of point forecasts adjusted and $p=0.0074$ for SAA). Similarly, the presumed credibility did not have a significant effect when the experienced credibility was high (Tukey's HSD for G1 vs. G3: $p>0.1$ for all measures).

For the adjustment of the initial interval widths, as measured by APAI, both the main effect of experienced credibility $\left(F_{1,61}=5.37, p=0.024, \eta_{p}^{2}=0.08\right)$ and its interaction with presumed credibility $\left(F_{1,61}=3.89, p=\right.$ $0.05, \eta_{p}^{2}=0.06$ ) were significant. The advice was least influential when the experienced credibility was low despite the source having a high presumed credibility. The pairwise comparisons also support this observation by showing that the difference was most extreme between the G1 and G2 (Tukey's HSD: $p=0.0149$ for APAI), whereas none of the other differences, including that between G1 and G3, were distinct enough to reach statistical significance (Tukey's HSD: $p>0.1$ for APAI).

\subsection{Results: advice utilization}

As with the previous experiments, the advice utilization scores were calculated for all but a single case where the initial point forecast was equal to the advice provided. For this case, no adjustment was made to the initial forecast, so scores of 0 for advice-shift and WoA and 1 for WoE were assigned. 'Ordinary' cases of advice utilization constituted $89.23 \%$ of the data. Table 8 shows the advice-shift, WoA and WoE for each source condition on the ordinary cases.

The $F$-test scores in Table 8 indicate significant differences among the four groups across all advice utilization 
Table 7

Judgmental adjustments on the initial forecasts in Experiment 3.

\begin{tabular}{|c|c|c|c|}
\hline Point forecasts & $\%$ of initial point forecasts adjusted & AAP & APAP \\
\hline Presumed high, experienced high (G1) & $\begin{array}{l}77.31 \% \\
(216)\end{array}$ & $\begin{array}{l}0.46 \\
(216)\end{array}$ & $\begin{array}{l}5.79 \% \\
(216)\end{array}$ \\
\hline Presumed high, experienced low (G2) & $\begin{array}{l}42.71 \% \\
(192)\end{array}$ & $\begin{array}{l}0.17 \\
(192)\end{array}$ & $\begin{array}{l}2.20 \% \\
(192)\end{array}$ \\
\hline Presumed low, experienced high (G3) & $\begin{array}{l}60.42 \% \\
(192)\end{array}$ & $\begin{array}{l}0.33 \\
(336)\end{array}$ & $\begin{array}{l}4.12 \% \\
(336)\end{array}$ \\
\hline \multirow[t]{2}{*}{ Presumed low, experienced low (G4) } & $\begin{array}{l}43.89 \% \\
(180)\end{array}$ & $\begin{array}{l}0.22 \\
(180)\end{array}$ & $\begin{array}{l}2.88 \% \\
(180)\end{array}$ \\
\hline & $\begin{array}{l}F_{3,61}=5.53, p=0.002 \\
\eta_{p}^{2}=0.21\end{array}$ & $\begin{array}{l}F_{3,61}=6.77, p=0.001 \\
\eta_{p}^{2}=0.25\end{array}$ & $\begin{array}{l}F_{3,61}=6.40, p=0.001 \\
\eta_{p}^{2}=0.24\end{array}$ \\
\hline Interval forecasts & $\%$ of initial interval forecasts adjusted & SAA & APAI \\
\hline Presumed high, experienced high (G1) & $\begin{array}{l}81.02 \% \\
(216)\end{array}$ & $\begin{array}{l}0.91 \\
(216)\end{array}$ & $\begin{array}{l}24.03 \% \\
(216)\end{array}$ \\
\hline Presumed high, experienced low (G2) & $\begin{array}{l}52.60 \% \\
(192)\end{array}$ & $\begin{array}{l}0.40 \\
(192)\end{array}$ & $\begin{array}{l}11.97 \% \\
(192)\end{array}$ \\
\hline Presumed low, experienced high (G3) & $\begin{array}{l}64.58 \% \\
(192)\end{array}$ & $\begin{array}{l}0.66 \\
(192)\end{array}$ & $\begin{array}{l}20.02 \% \\
(192)\end{array}$ \\
\hline \multirow[t]{2}{*}{ Presumed low, experienced low (G4) } & $\begin{array}{l}50.56 \% \\
(180)\end{array}$ & $\begin{array}{l}0.46 \\
(180)\end{array}$ & $\begin{array}{l}19.05 \% \\
(180)\end{array}$ \\
\hline & $\begin{array}{l}F_{3,61}=4.97, p=0.011 \\
\eta_{p}^{2}=0.20\end{array}$ & $\begin{array}{l}F_{3,61}=6.05, p=0.001 \\
\eta_{p}^{2}=0.23\end{array}$ & $\begin{array}{l}F_{3,61}=3.29, p=0.026 \\
\eta_{p}^{2}=0.14\end{array}$ \\
\hline
\end{tabular}

Note: the numbers in parentheses indicate the numbers of observations in each category.

Table 8

Mean advice utilization scores for ordinary cases in Experiment 3.

\begin{tabular}{|c|c|c|c|}
\hline & Advice-shift & WoA & WoE \\
\hline Presumed high, experienced high (G1) & $\begin{array}{l}0.46 \\
(18)\end{array}$ & $\begin{array}{l}0.45 \\
(18)\end{array}$ & $\begin{array}{l}0.52 \\
(18)\end{array}$ \\
\hline Presumed high, experienced low (G2) & $\begin{array}{l}0.15 \\
(16)\end{array}$ & $\begin{array}{l}0.16 \\
(16)\end{array}$ & $\begin{array}{l}0.83 \\
(16)\end{array}$ \\
\hline Presumed low, experienced high (G3) & $\begin{array}{l}0.31 \\
(16)\end{array}$ & $\begin{array}{l}0.31 \\
(16)\end{array}$ & $\begin{array}{l}0.66 \\
(16)\end{array}$ \\
\hline \multirow[t]{2}{*}{ Presumed low, experienced low (G4) } & $\begin{array}{l}0.16 \\
(15)\end{array}$ & $\begin{array}{l}0.18 \\
(15)\end{array}$ & $\begin{array}{l}0.82 \\
(15)\end{array}$ \\
\hline & $\begin{array}{l}F_{3,61}=9.54, p<0.001 \\
\eta_{p}^{2}=0.32\end{array}$ & $\begin{array}{l}F_{3,61}=8.69, p<0.001 \\
\eta_{p}^{2}=0.30\end{array}$ & $\begin{array}{l}F_{3,61}=9.20, p<0.001 \\
\eta_{p}^{2}=0.31\end{array}$ \\
\hline
\end{tabular}

Note: the numbers in parentheses indicate the numbers of participants in each category.

scores. The $2 \times 2$ factorial ANOVA reveals a significant main effect of the experienced credibility factor $\left(F_{1,61}=\right.$ 23.03, $p<0.001, \eta_{p}^{2}=0.27$ for advice-shift; $F_{1,61}=$ $20.44, p<0.001, \eta_{p}^{2}=0.25$ for WoA; $F_{1,61}=23.05, p<$ $0.001, \eta_{p}^{2}=0.27$ for WoE). In addition, neither the main effect of the presumed credibility nor its interaction with the experienced credibility were found to be significant (all $p>0.05$ ). As with the results observed for judgmental adjustments, the utilization of a source's advice is the greatest when it has high presumed and experienced credibility, relative to a source with a low experienced credibility (Tukey's HSD for G1 vs. G2: $p=0.0001$ for advice-shift, $p=0.0002$ for WoA and $p=0.0002$ for WoE; Tukey's HSD for G1 vs. G4: $p=0.0003$ for advice-shift, $p=0.0006$ for WoA and $p=0.0004$ for WoE). Again, the presumed credibility does not seem to affect advice acceptance if the perception about the source formed through experi- ence is high (Tukey's HSD for G1 vs. G3: $p>0.1$ for all measures).

Overall, the results from Experiment 3 generally suggest that when the forecasters have presumptions about a source's credibility and also experience the source's accuracy over time, the perceptions formed through experience dominate. This conforms to the 'experience-only' model in Fig. 1(b). The only exception relates to the interval widths, as measured by the APAI, where there was a significant interaction between the two types of credibility. It is not clear why the results for the APAI followed a different pattern.

\section{Experiment 4-experienced and presumed credibility}

The design and procedure of this study were identical to those of Experiment 3; the only difference was that it involved professionals as participants. A total of 82 


\begin{tabular}{lll}
\hline & $\begin{array}{l}\text { High presumed credibility } \\
\text { "Source of this forecast advice is a well-known } \\
\text { financial analyst with extensive knowledge on } \\
\text { stock price forecasting" }\end{array}$ & $\begin{array}{l}\text { Low presumed credibility } \\
\text { "Source of this forecast advice is a taxi } \\
\text { driver" }\end{array}$ \\
\hline $\begin{array}{l}\text { High experienced credibility } \\
\text { [Initial } 12 \text { experience-building series had a }\end{array}$ & $\begin{array}{l}\text { \# of participants: } 21 \\
\text { Mean work XP: } 9.3\end{array}$ & $\begin{array}{l}\text { \# of participants: } 20 \\
\text { Mean work XP: } 12.1\end{array}$ \\
$\begin{array}{l}\text { MAPE of } 2.94 \% \text { for the point forecasts and a hit } \\
\text { rate of } 83 \% \text { for the intervals] }\end{array}$ & $\begin{array}{l}\text { Mean age: } 32.9 \\
\text { (G1) }\end{array}$ & Mean age: 35.2 \\
Low experienced credibility & \# of participants: 21 & \# of participants: 20 \\
[Initial 12 experience-building series had a & Mean work XP: 10.8 & Mean work XP: 7.4 \\
MAPE of $14.94 \%$ for the point forecasts and a hit & Mean age: 34.1 & Mean age: 31.2 \\
rate of $17 \%$ for the intervals] & (G2) & (G4)
\end{tabular}

Note: the numbers in the cells indicate the numbers of professional participants, average years of work experience and average age, with the group codes shown in parentheses.

professionals who regularly receive or give financial advice in sectors such as banking, finance, defense, energy and IT, participated; Table 9 displays the work experience and age details for this participant pool.

\subsection{Results: judgmental adjustments of the initial forecasts}

Table 10 displays the $F$-test scores of the four credibility groups for measures of adjustment size, showing significant differences among the groups (APAP, AAP, SAA), with the exception of APAI. In terms of adjustment frequencies, all groups' scores were statistically similar. Further $2 \times 2$ factorial ANOVA analyses, which take into account the repeated measures design of the experiment, were run to investigate the factor effects that generated these distinctions.

For point forecasts, both the experienced credibility $\left(F_{1,78}=5.08, p=0.027, \eta_{p}^{2}=0.06\right.$ for AAP; $F_{1,78}=5.65$, $p=0.02, \eta_{p}^{2}=0.07$ for APAP) and the presumed credibility $\left(F_{1,78}=7.79, p=0.007, \eta_{p}^{2}=0.09\right.$ for AAP; $F_{1,78}=7.23, p=0.009, \eta_{p}^{2}=0.08$ for APAP) appeared to have significant influences on the adjustment size. The interaction effect between experienced and presumed credibility was not significant $(p>0.05)$. Pairwise comparisons among the groups revealed that the high presumed and experienced credibility group (i.e., G1) made significantly larger adjustments than the group given advice from a low presumed credibility source while also experiencing low credibility (i.e., G4) (Tukey's HSD for G1 vs. G4: $p=0.0034$ for AAP and $p=0.0033$ for APAP). None of the other differences among the groups were strong enough to attain statistical significance (Tukey's HSD: $p>0.1$ ).

For interval forecasts, parallel findings were observed only for SAA scores. For the size of the adjustments on the interval bounds (as operationalized by SAA), there were significant main effects of both the presumed $\left(F_{1,78}=\right.$ 7.34, $\left.p=0.008, \eta_{p}^{2}=0.09\right)$ and experienced $\left(F_{1,78}=\right.$ 13.08, $\left.p=0.001, \eta_{p}^{2}=0.14\right)$ credibility. The interaction effect was insignificant. Pairwise comparisons on SAA suggested that the high presumed and experienced credibility group made significantly larger adjustments than the groups experiencing low credibility (Tukey's HSD for G1 vs. G2: $p=0.0341$; Tukey's HSD for G1 vs. G4: $p=0.0002$ ). The presumed credibility did not have a significant effect when the experienced credibility was high (Tukey's HSD for G1 vs. G3: $p>0.1$ ), and the remaining pairwise differences were also insignificant (Tukey's HSD $p>0.1$ ). Interestingly, the presumed and experienced credibility factors were not influential in differentiating the sizes of interval widths, as measured by APAI. Even though there were distinct adjustments to the interval bounds (as designated by SAA scores), the changes in widths between the initial and final intervals remained nearly the same across all groups.

\subsection{Results: advice utilization}

As in the analyses of previous experiments, the advice utilization scores were calculated for all but the rare cases (12 out of 984) where the initial point forecast was exactly equal to the advice provided. In three of these cases, the initial predictions were also equal to the final forecasts, so they were assigned perfect discounting scores ( 0 for advice-shift and WoA, 1 for $\mathrm{WoE}$ ). The remaining nine cases were omitted from the calculations. 'Ordinary' cases of advice utilization constituted $71.24 \%$ of the data, and the remaining $28.46 \%$ cases were classified as 'extraordinary'. These extraordinary adjustments were not only more numerous for the professionals' predictions than for the students' predictions, they also contained quite extreme cases. As in the case of the students' predictions in Experiment 3, the subsequent analysis (as displayed in Table 11) was conducted for the ordinary cases of advice utilization.

The $F$-test scores in Table 11 indicate significant differences among the four groups across all three scores. The $2 \times 2$ factorial ANOVA reveals that there are significant main effects of both the experienced credibility factor $\left(F_{1,78}=5.60, p=0.020, \eta_{p}^{2}=0.07\right.$ for advice-shift; $F_{1,78}=6.32, p=0.014, \eta_{p}^{2}=0.07$ for WoA; and $F_{1,78}=$ 5.25, $p=0.025, \eta_{p}^{2}=0.06$ for $\left.\mathrm{WoE}\right)$ and the presumed credibility factor $\left(F_{1,78}=7.24, p=0.009, \eta_{p}^{2}=0.08\right.$ for advice-shift; $F_{1,78}=4.80, p=0.032, \eta_{p}^{2}=0.06$ for WoA; and $F_{1,78}=6.40, p=0.013, \eta_{p}^{2}=0.08$ for WoE) across all utilization scores. None of the interaction effects are significant (all $p>0.05$ ). As with the results observed for judgmental adjustments, the utilization of its advice is highest when a source has high presumed and experienced credibility, relative to a source with low experienced and presumed credibility (Tukey's HSD for G1 vs. G4: $p=0.0033$ 
Table 10

Judgmental adjustments to initial forecasts.

\begin{tabular}{|c|c|c|c|}
\hline Point forecasts & $\%$ of initial point forecasts adjusted & AAP & APAP \\
\hline Presumed high, experienced high (G1) & $\begin{array}{l}84.92 \% \\
(252)\end{array}$ & $\begin{array}{l}0.41 \\
(252)\end{array}$ & $\begin{array}{l}5.05 \% \\
(252)\end{array}$ \\
\hline Presumed high, experienced low (G2) & $\begin{array}{l}79.37 \% \\
(252)\end{array}$ & $\begin{array}{l}0.32 \\
(252)\end{array}$ & $\begin{array}{l}3.87 \% \\
(252)\end{array}$ \\
\hline Presumed low, experienced high (G3) & $\begin{array}{l}84.17 \% \\
(240)\end{array}$ & $\begin{array}{l}0.30 \\
(240)\end{array}$ & $\begin{array}{l}3.73 \% \\
(240)\end{array}$ \\
\hline \multirow[t]{2}{*}{ Presumed low, experienced low (G4) } & $\begin{array}{l}82.08 \% \\
(240)\end{array}$ & $\begin{array}{l}0.23 \\
(240)\end{array}$ & $\begin{array}{l}2.78 \% \\
(240)\end{array}$ \\
\hline & N.S. & $\begin{array}{l}F_{3,78}=4.32, p=0.007 \\
\eta_{p}^{2}=0.14\end{array}$ & $\begin{array}{l}F_{3,78}=4.33, p=0.007 \\
\eta_{p}^{2}=0.14\end{array}$ \\
\hline Interval forecasts & $\%$ of initial interval forecasts adjusted & SAA & APAI \\
\hline Presumed high, experienced high (G1) & $\begin{array}{l}96.03 \% \\
(252)\end{array}$ & $\begin{array}{l}1.04 \\
(252)\end{array}$ & $\begin{array}{l}139.30 \% \\
(252)\end{array}$ \\
\hline Presumed high, experienced low (G2) & $\begin{array}{l}90.48 \% \\
(252)\end{array}$ & $\begin{array}{l}0.75 \\
(252)\end{array}$ & $\begin{array}{l}92.49 \% \\
(252)\end{array}$ \\
\hline Presumed low, experienced high (G3) & $\begin{array}{l}94.58 \% \\
(240)\end{array}$ & $\begin{array}{l}0.82 \\
(240)\end{array}$ & $\begin{array}{l}104.70 \% \\
(240)\end{array}$ \\
\hline \multirow[t]{2}{*}{ Presumed low, experienced low (G4) } & $\begin{array}{l}92.08 \% \\
(240)\end{array}$ & $\begin{array}{l}0.57 \\
(240)\end{array}$ & $\begin{array}{l}108.80 \% \\
(240)\end{array}$ \\
\hline & N.S. & $\begin{array}{l}F_{3,78}=6.85, p<0.0001 \\
\eta_{p}^{2}=0.21\end{array}$ & N.S. \\
\hline
\end{tabular}

Note: the numbers in parentheses indicate the numbers of observations in each category.

Table 11

Mean advice utilization scores for ordinary cases in professionals' forecasts.

\begin{tabular}{|c|c|c|c|}
\hline & Advice-shift & WoA & WoE \\
\hline Presumed high, experienced high (G1) & $\begin{array}{l}0.45 \\
(21)\end{array}$ & $\begin{array}{l}0.45 \\
(21)\end{array}$ & $\begin{array}{l}0.52 \\
(21)\end{array}$ \\
\hline Presumed high, experienced low (G2) & $\begin{array}{l}0.36 \\
(21)\end{array}$ & $\begin{array}{l}0.34 \\
(21)\end{array}$ & $\begin{array}{l}0.62 \\
(21)\end{array}$ \\
\hline Presumed low, experienced high (G3) & $\begin{array}{l}0.34 \\
(20)\end{array}$ & $\begin{array}{l}0.36 \\
(20)\end{array}$ & $\begin{array}{l}0.63 \\
(20)\end{array}$ \\
\hline \multirow[t]{2}{*}{ Presumed low, experienced low (G4) } & $\begin{array}{l}0.25 \\
(20)\end{array}$ & $\begin{array}{l}0.26 \\
(20)\end{array}$ & $\begin{array}{l}0.72 \\
(20)\end{array}$ \\
\hline & $\begin{array}{l}F_{3,78}=4.28, p=0.007 \\
\eta_{p}^{2}=0.14\end{array}$ & $\begin{array}{l}F_{3,78}=3.73, p=0.015 \\
\eta_{p}^{2}=0.13\end{array}$ & $\begin{array}{l}F_{3,78}=3.89, p=0.012 \\
\eta_{p}^{2}=0.13\end{array}$ \\
\hline
\end{tabular}

Note: the numbers in parentheses indicate the numbers of participants in each category.

for advice-shift, $p=0.0072$ for WoA and $p=0.0056$ for $\mathrm{WoE}$ ). The remaining pairwise differences are all insignificant (Tukey's HSD: $p>0.1$ ).

Overall, the professional's use of advice conformed with the 'presumption + advice' model (Fig. 1(c)). None of the measures were consistent with the effects predicted by either the disconfirmation or ideal points models.

\subsection{Results: comparisons with findings of Experiment 3}

Experiments 3 and 4 were identical except for their participants (i.e., students in Experiment 3 vs. professionals in Experiment 4). Thus, a comparison of their findings is important in enhancing our understanding of the way in which expert advice is used in forecasting.

In terms of the frequency of adjustments (percentage of initial point and interval forecasts adjusted), the professionals consistently adjusted a very high percentage $(>79 \%)$, regardless of the credibility group to which they belonged. The adjustment frequency was not influenced by either the experienced or presumed credibility of the forecast source. This is in line with extant work (e.g., Fildes, Goodwin, Lawrence, \& Nikolopoulos, 2009 and Önkal \& Gönül, 2005), showing that, for a number of reasons, professionals almost always intervene to adjust the forecasts they receive.

The second main difference between the students and professionals was that, for the students, the presumed credibility did not have any significant effect on any of the measures (except the APAI) relating to the size of adjustments and the utilization of advice when experienced credibility was present. Thus, when the students had access to the track record of the advisor, this generally eclipsed any considerations of the advisor's status. In contrast, the professionals were influenced by both experienced and presumed credibility. When these were low, they both led to significantly larger adjustments and lower advice utilization. Hence, the professionals were sensitive to the advisor's status even when their track record was 
available. Thus, while the students' use of advice was generally consistent with the experience-only model, the professionals conformed to the experience + presumption model.

The third difference was that the professionals did not make any significant changes to the width of their prediction intervals after receiving the advice. Hence, their adjustments to the bounds of their intervals served only to shift them to a new location. In contrast, the students did make significant changes to the widths of their intervals, depending on the interaction between the experienced and presumed credibility of their advisor.

\section{General discussion}

Our four studies indicate that, when considered separately, both the presumed and experienced credibility of an advisor/expert can have a significant effect on the extent to which users revise their prior forecasts, irrespective of whether these are expressed as point or interval forecasts. However, when both forms of credibility are available, the influence of the advice differs between non-professional and professional advisees.

For non-professionals, with the exception of interval widths, there is no evidence that the presumed credibility has any influence on advisees when the experienced credibility is high. For professionals, who were perhaps sensitive to their own status, the relative status of the advisor, as reflected by their presumed credibility, was influential. No evidence was found to support either the 'Presumption-only' or 'Disconfirmation' models. The first of these might apply only when advisees are not motivated to examine an advisor's record or have an inaccurate recall of this record. In Experiments 3 and 4, the participants were presented with the record just before they made their forecasts. The absence of evidence for the disconfirmation and ideal points models suggests that surprises or disappointments, where an advisor's performance differs from that which would be presumed, do not affect the influence of advice. For the students, this appears to be because the advisor's status was ignored when their track record was available. On the other hand, the professionals did not react to such contradictions even though they were sensitive to the status of the advisor, possibly because their experience of financial forecasting meant that they were less surprised when people with high presumed credibility were found to have poor track records, and vice versa.

No rationale was given for the advisor's forecasts, so participants' assessments of the expert's credibility were not confounded with judgments about the plausibility of the reasons for the advisor's forecasts. In the study of presumed credibility (Experiment 2), Tables 4 and 5 show that people in the control and high presumed credibility groups typically made similar adjustments to their initial forecasts, while those in the low presumed credibility group made smaller adjustments. Thus, the presumption of a high credibility did not increase the adjustments relative to unattributed advice. This suggests that the default position for the advice appearing on the computer screen was that it had presumed credibility even if its source was unknown, a finding that is consistent with truth-bias.
Hence, the information about the status of the source only made a difference when it had a negative effect. However, even this difference was relatively small, suggesting that the presumed credibility of a source based on its status does not have a strong effect.

A different and stronger effect was found in the case of experienced credibility. Here, it was the low experienced credibility group that typically produced forecasts that were similar to those of the control group. Thus, experience of highly accurate forecasts enhanced the credibility of the source, relative to the control, but being presented with a sample of relatively inaccurate forecasts did not detract from it. Several studies have found that people have a high propensity to adjust, heavily discount or ignore, provided forecasts, whether they come from a statistical method (e.g., Fildes et al., 2009) or a human expert (e.g., Önkal et al., 2009). At the extreme, discounting can involve totally ignoring advice. Neither the control group nor those who experienced inaccurate forecasts from the advisor had any reason to attach credibility to the advised forecasts. Hence, they may well have both discounted at this extreme level, with their own forecasts replacing the provided forecasts rather than adjusting them. Accordingly, an absence of experienced credibility appears to lead to the same effect as experience indicating low credibility. Only those experiencing highly accurate forecasts would have had any reason to have developed a positive perception of their credibility and to have paid some attention to them.

Overall, experienced credibility was more influential than presumed credibility. In Experiments 3 and 4, information on the status of the advisor was displayed on the computer screen after the track record of the advisor. This means that explanations based on the greater recency of experience cannot apply here. It is more likely that the information on accuracy was more congruent with the objectives of the task than the information on status (e.g., Bettman \& Zins, 1979). The former was displayed in a graphical format, the forecast adjustments were made on graphs too, and accuracy was directly relevant to what the participants wanted to achieve. Highly accurate or highly inaccurate forecasts would have had high levels of salience to the participants, so that the attention paid to the advisor's accuracy would probably have been greater than that paid to their status.

In all cases, people were generally prepared to change a large percentage of their original forecasts when they received the advice, despite receiving no rationale to accompany it. To some extent, this may be an artifact of experiments like this. People may feel obliged to make adjustments because they feel that this is expected, especially if they have been recruited because of their professional status; otherwise, why are they repeatedly being invited to make adjustments? However, a similar phenomenon has been found in field studies, where professional forecasters have been found to make large numbers of unnecessary small adjustments to statistical forecasts, apparently merely to register that they are doing their job (e.g., Fildes et al., 2009).

This work has a number of limitations and could also be extended in several ways. Business undergraduates 
may not be typical of the people making stock market forecasts and decisions. To some extent, they may be more knowledgeable than typical investors, as they will have been taught courses in forecasting and finance. However, since the task did not include contextual information like stock names, any expertise that business students had about stocks was not directly useful for these anonymous stocks. Nevertheless, both they and the professionals were prepared to make judgments on the basis of presumptions about expertise that have little empirical justification (i.e., that 'experts' produce more accurate stock market forecasts) and on the basis of relatively small samples of experienced accuracy. Of course, the errors in their forecasts did not carry the risks of financial losses or missed gains that would apply in real investing, but their responses to the stimuli, and the informal feedback, suggest that they took the task seriously and engaged in it with interest. The experiments were conducted as forecasting competitions and we observed that this motivated them strongly, as they strove to outperform their colleagues.

Another potential limitation could involve the experimental design of Experiments 3 and 4, as these studies did not aim to control for the time spent on manipulation. For experienced credibility, the participants may have chosen to spend more time examining the performance on the trials, which may then make the experienced credibility more salient; whereas for the presumed credibility, the participants are just told about the person's reputation, with potentially limited time being spent on this part of the task. It could be that spending more time reading about advisor's presumed credibility might make it more powerful. Further work could benefit from incorporating such manipulation checks, as well as from including advisor and advisee confidence as potentially important signals for tracking advice use (Sah et al., 2013).

The experiments involved only three levels of presumed and experienced credibility (low, none and high). In future, it may be worth testing the effects at more levels. For example, in the context of information systems adoption, Venkatesh and Goyal (2010) found non-linear relationships between people's willingness to adopt systems and a range of values of expectations and experience relating to the usefulness of a system. In addition, it would be worth exploring the effect of presumed and experienced credibility when the advisor provides a justification for their forecast, as this situation is often encountered in practice.

Along the lines suggested in EKE research, another promising research direction would be to investigate combinations of elicited knowledge from multiple experts (Aspinall, 2010; US EPA, 2009) or expert panels (Budnitz et al., 1998) under conditions of varying credibility levels. This would be especially critical for enhancing the effectiveness of the Delphi (Bolger \& Rowe, 2014; Bolger \& Wright, 2011; Rowe, Wright, \& McColl, 2005) and scenario (Önkal, Sayım, \& Gönül, 2013; Wright, Bradfield, \& Cairns, 2013; Wright \& Goodwin, 2009) methodologies in organizational forecasting processes. Such work promises to enhance our understanding of the ways in which forecast users and decision makers actually assess expert advice, and how this evaluation process can be effectively supported.

\section{Conclusions}

Our studies indicate that, in forecasting, the weighting that is attached implicitly to expert advice depends more on the observed accuracy of the advisor than on presumptions about the advisor's status. However, presumptions about the status of the advisor are influential when no accuracy track record is available or when professionals are the recipients of the advice, rather than students. These results have a number of implications for expert knowledge elicitation (EKE). First, there is plenty of evidence that, in many fields, apparent expertise is not correlated with forecasting accuracy. Also, more accurate forecasts can be obtained from diverse groups of people, some of whom may not be regarded as experts (e.g., Tetlock \& Gardner, 2015). This suggests that, in forecasting, presumed credibility may often be misleading as an indication of the relative value of an expert's judgments. In these cases, EKE methods that protect the anonymity of experts, such as the Delphi method, are likely to be advantageous.

Secondly, both students and professionals were prepared to change their initial forecasts on the basis of a limited sample of evidence about the advisor's track record. This was in spite the fact that, especially in financial forecasting, a forecaster's past record can be a very poor guide to their future accuracy (e.g., Taleb, 2004). This suggests that in EKE processes, when experts' judgments are being selected or implicitly weighted, track records should only be used when they provide a reliable indication of an expert's likely future performance. When this is not possible, information on track records should be suppressed. A better indication of the quality of a judgment may be the rationale that underlies it. The circulation of arguments that justify forecasts has been found to lead to improvements in the accuracy of forecasts obtained using Delphi applications (Wright \& Rowe, 2011).

\section{Appendix A}

Experiment 1: Experience-building stage.

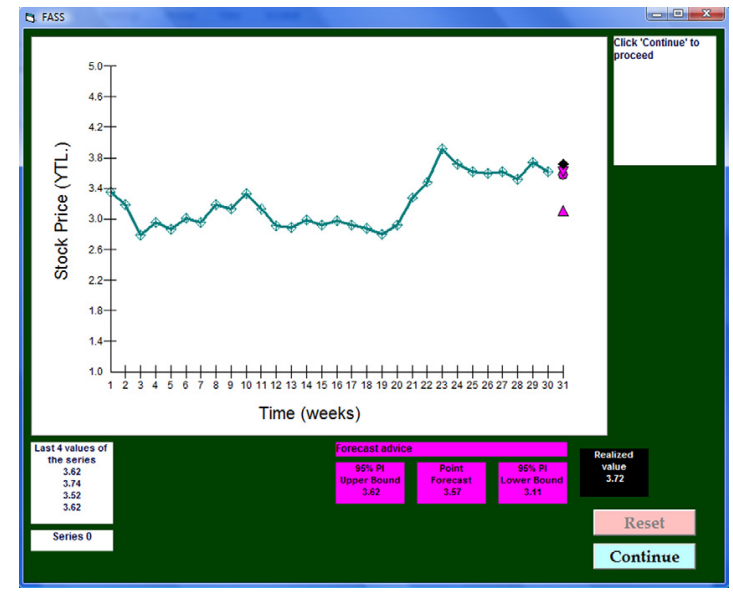


Experiment 1: Forecasting-judgmental adjustment phase for the practice series.

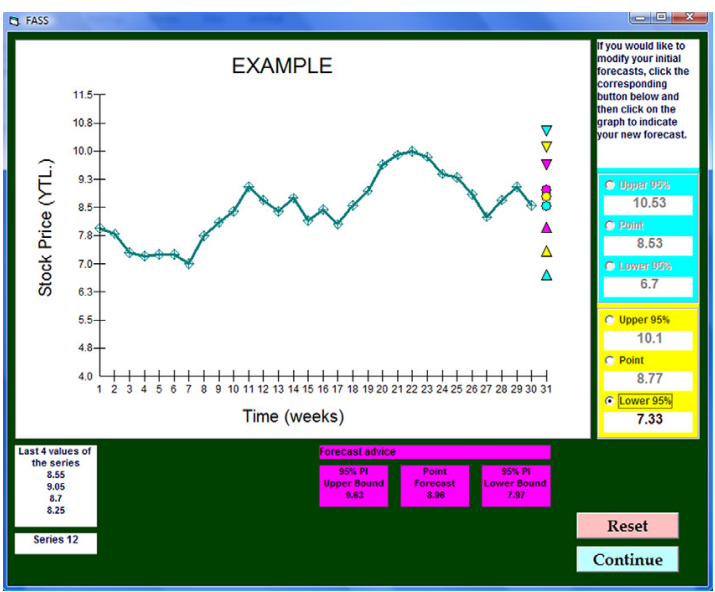

Cyan marks: participants' initial predictions. Magenta marks: provided forecasting advice. Yellow marks: final adjusted forecasts given by participants.

\section{Appendix B}

Experiment 2: Practice series for the low presumed credibility group.

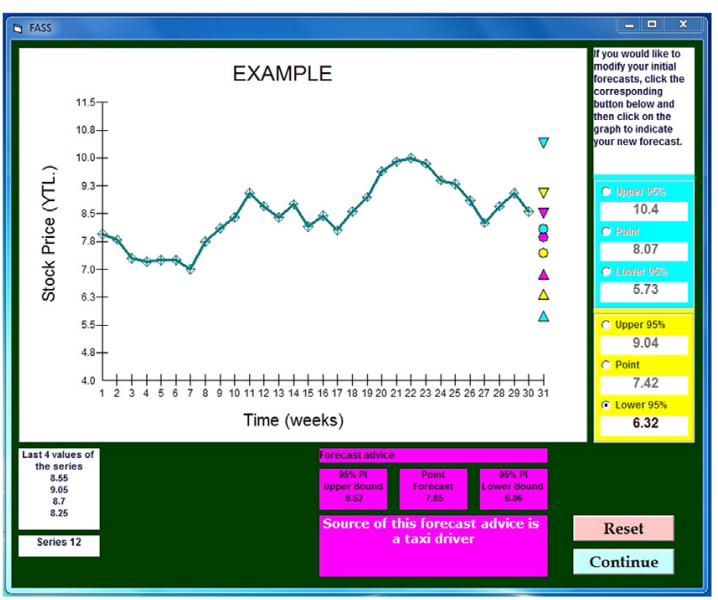

Cyan marks: participants' initial predictions. Magenta marks: provided forecasting advice. Yellow marks: final adjusted forecasts given by participants.

\section{Appendix C. Supplementary data}

Supplementary material related to this article can be found online at http://dx.doi.org/10.1016/j.ijforecast.2015. 12.009 .

\section{References}

Anderson, R. E. (1973). Consumer dissatisfaction: the effect of disconfirmed expectancy on perceived product performance. Journal of Marketing Research, 10(1), 38-44.

Armstrong, J. S. (1980). The seer-sucker theory: the value of experts in forecasting. Technology Review, 82, 16-24.

Aspinall, W. (2010). A route to more tractable expert advice. Nature, 463, 294-295.

Berger, J., Fisek, M. H., Norman, R. Z., \& Zelditch, M., Jr. (1977). Status characteristics and social interaction: an expectation states approach. New York: Elsevier:

Berry, T. R., \& Shields, C. (2014). Source attributions and credibility of health and appearance exercise advertisements: relationships with implicit and explicit attitudes and intensions. Journal of Health Psychology, 19, 242-252.

Bettman, J. R., \& Zins, M. A. (1979). Information format and choice task effects in decision making. Journal of Consumer Research, 6, 141-153.

Bhattacherjee, A. (2001). Understanding information systems continuance: an expectation-confirmation model. MIS Quarterly, 25, $351-370$.

Bolger, F., \& Rowe, G. (2014). Delphi: somewhere between Scylla and Charybdis? Proceedings of the National Academy of Sciences of the United States of America, 111(41), pp. E4284.

Bolger, F., \& Rowe, G. (2015). The aggregation of expert judgment: do good things come to those who weight? Risk Analysis, 35, 5-11.

Bolger, F., \& Wright, G. (2011). Improving the Delphi process: Lessons from social psychological research. Technological Forecasting and Social Change, 78, 1500-1513.

Bonaccio, S., \& Dalal, R. S. (2006). Advice taking and decision-making: An integrative literature review, and implications for the organizational sciences. Organizational Behavior and Human Decision Processes, 101, $127-151$.

Bonaccio, S., \& Dalal, R. S. (2010). Evaluating advisors: A policy-capturing study under conditions of complete and missing information. Journal of Behavioral Decision Making, 23, 227-249.

Brown, S. A., Venkatesh, V., Kuruzovich, J., \& Massey, A. P. (2008). Expectation confirmation: an examination of three competing models. Organizational Behavior and Human Decision Processes, 105, 52-66.

Budnitz, R. J., Apostolakis, G., Boore, D. M., Cluff, L. S., Coppersmith, K. J., Cornell, C. A., \& Morris, P. A. (1998). Use of technical expert panels: applications to probabilistic seismic hazard analysis. Risk Analysis, 18 , 463-469.

Budnitz, R.J., Boore, D.M., Apostolakis, G., Cluff, L.S., Coppersmith, K.J., Cornell, C.A., \& Moms, P.A. (1995). Recommendations for probabilistic seismic hazard analysis: guidance on uncertainty and use of experts, Vol. 1, Washington, DC: US Nuclear Regulatory Commission.

Carlsmith, J. M., \& Aronson, E. (1963). Some hedonic consequences of the confirmation and disconfirmation of expectancies. Journal of Abnormal Social Psychology, 66, 151-156.

Chen, W., \& Tan, H.-T. (2013). Judgment effects of familiarity with an analyst's name. Accounting, Organisations and Society, 38, 214-227.

Cooke, R. M. (1991). Experts in uncertainty: opinion and subjective probability in science. Oxford: Oxford University Press.

Correll, S. J., \& Ridgeway, C. L. (2003). Expectation states theory. In J. Delamater (Ed.), Handbook of social psychology. New York: Kluwer Academic/Plenum Publishers.

Dholakia, R.R. (1986). Source credibility effects: A test of behavioural persistence. In M. Wallendorf, P. Anderson (Eds.), Advances in consumer research, Provo, UT: Association of Consumer Research Vol. 14 (pp. 426-430).

Dholakia, R. R., \& Strenthal, B. (1977). Highly credible sources: persuasive facilitators or persuasive liabilities. Journal of Consumer Research, 3, $223-232$.

Elliot, A. J., \& Devine, P. G. (1994). On the motivational nature of cognitive dissonance: dissonance as psychological discomfort. Journal of Personality and Social Psychology, 67, 382-394.

Festinger, L. A. (1957). A theory of cognitive dissonance. Stanford, CA: Stanford University Press.

Fildes, R., Goodwin, P., Lawrence, M., \& Nikolopoulos, K. (2009). Effective forecasting and judgmental adjustments: an empirical evaluation and strategies for improvement in supply-chain planning. International Journal of Forecasting, 25, 3-23.

Fogg, B. J. (1999). Persuasive technologies-Now is your chance to decide what they will persuade us to do-and how they'll do it. Communications of the ACM, 42, 26-29.

Gardner, D. (2011). Future babble. Toronto: McClelland and Stewart.

Gönül, M. S., Önkal, D., \& Goodwin, P. (2009). Expectations, use and judgmental adjustment of external financial and economic forecasts: an empirical investigation. Journal of Forecasting, 28, 19-37. 
Gönül, M. S., Önkal, D., \& Lawrence, M. (2006). The effects of structural characteristics of explanations on the use of a DSS. Decision Support Systems, 42(3), 1481-1493.

Goodwin, P., Gönül, M. S., \& Önkal, D. (2013). Antecedents and effects of trust in forecasting advice. International Journal of Forecasting, 29, 354-366.

Goodwin, P., \& Wright, G. (2014). Decision analysis for management judgment (5th ed.). Chichester: Wiley.

Harvey, N., \& Fischer, I. (1997). Accepting help, improving judgment, and sharing responsibility. Organizational Behavior and Human Decision Processes, 70(2), 117-133.

Harvey, N., Harries, C., \& Fischer, I. (2000). Using advice and assessing its quality. Organizational Behavior and Human Decision Processes, 81 , $252-273$.

Hirst, D. E., Koonce, L., \& Miller, J. (1999). The joint effect of management's prior forecast accuracy and the form of its financial forecasts on investor judgment. Journal of Accounting Research, 37, 101-124.

Hovland, C. I., \& Weiss, W. (1951). The influence of source credibility on communication effectiveness. Public Opinion Quarterly, 15, 635-650.

Irving, P. G., \& Meyer, J. P. (1994). Reexamination of the met-expectations hypothesis: A longitudinal analysis. Journal of Applied Psychology, 79, 937-949.

Johnson, H. H., \& Izzett, R. (1969). Relationship between authoritarianism and attitude change as a function of source credibility and type of communication. Journal of Personality and Social Psychology, 13, $317-321$

Kahneman, D. (2011). Thinking fast and slow. New York: Farrar, Straus and Giroux.

Kelman, H. C., \& Hovland, C. I. (1953). Reinstatement of the communicator in delayed measurement of opinion change. Journal of Abnormal and Social Psychology, 48, 327-335.

Lev, B., \& Penman, S. H. (1990). Voluntary forecast disclosure, nondisclosure and stock prices. Journal of Accounting Research, 28, 49-76.

Levine, T. R., \& McCornack, S. A. (1991). The dark side of trust: Conceptualizing and measuring types of communicative suspicion. Communication Monographs, 39, 325-340.

Levine, T. R., Park, H. S., \& McCornack, S. A. (1999). Accuracy in detecting truths and lies: Documenting the "veracity effect". Communication Monographs, 66, 125-144.

Lim, J. S., \& O'Connor, M. (1995). Judgmental adjustment of initial forecasts-its effectiveness and biases. Journal of Behavioral Decision Making, 8, 149-168.

Lirtzman, S. I., \& Shuv-Ami, A. (1986). Credibility of source communication on products' safety hazards. Psychological Reports, 58, 235-244.

McKnight, D.H., \& Kacmar, C.J. (2007). Factors and effects of information credibility. ICEC'07, August 19-22, Minneapolis, Minnesota, USA.

Meyer, M. A., \& Booker, J. M. (1991). Eliciting and analyzing expert judgment: a practical guide. London: Academic Press.

Morgan, M. G. (2014). Use (and abuse) of expert elicitation in support of decision making for public policy. Proceedings of the National Academy of Sciences of the United States of America, 111, 7176-7184.

Morgan, M. G., \& Henrion, M. (1990). Uncertainty: a guide to dealing with uncertainty in quantitative risk and policy analysis. Cambridge: Cambridge University Press.

Oliver, R. L. (1977). Effect of expectation and disconfirmation on postexposure product evaluations: an alternative interpretation. Journal of Applied Psychology, 62(4), 480-486.

Oliver, R. L. (1980). A cognitive model for the antecedents and consequences of satisfaction. Journal of Marketing Research, 17(4), $460-469$

Önkal, D., \& Gönül, M. S. (2005). Judgmental adjustment: a challenge for providers and users of forecasts. Foresight: The International Journal of Applied Forecasting, 1, 13-17

Önkal, D., Gönül, M. S., \& Lawrence, M. (2008). Judgmental adjustments of previously-adjusted forecasts. Decision Sciences, 39(2), 213-238.

Önkal, D., Goodwin, P., Thomson, M., Gönül, M. S., \& Pollock, A. (2009). The relative influence of advice from human experts and statistical methods on forecast adjustments. Journal of Behavioral Decision Making, 22, 390-409.

Önkal, D., Sayım, K. Z., \& Gönül, M. S. (2013). Scenarios as channels of forecast advice. Technological Forecasting and Social Change, 80, $772-788$

Pornpitakpan, C. (2004). The persuasiveness of source credibility: A critical review of five decades' evidence. Journal of Applied Social Psychology, 34, 243-281.

Porter, L. W., \& Steers, R. M. (1973). Organizational, work, and personal factors in employee turnover and absenteeism. Psychological Bulletin, 80, 151-176.

Rhine, R., \& Severance, L. (1970). Ego-involvement, discrepancy, source credibility and attitude change. Journal of Personality and Social Psychology, 16, 175-190.
Rowe, G., Wright, G., \& McColl, A. (2005). Judgment change during Delphi-like procedures: The role of majority influence, expertise, and confidence. Technological Forecasting and Social Change, 72, 377-399.

Sah, S., Moore, D. A., \& MacCoun, R. J. (2013). Cheap talk and credibility: The consequences of confidence and accuracy on advisor credibility and persuasiveness. Organizational Behavior and Human Decision Processes, 121, 246-255.

See, K. E., Morrison, E. W., Rothman, N. B., \& Soll, J. B. (2011). The detrimental effects of power on confidence, advice taking, and accuracy. Organizational Behavior and Human Decision Processes, 116 $272-285$.

Sniezek, J. A., \& Van Swol, L. M. (2001). Trust, confidence, and expertise in a judge-advisor system. Organizational Behavior and Human Decision Processes, 84, 288-307

Soll, J. B., \& Larrick, R. (2009). Strategies for revising judgment: how (and how well) people use others' opinions. Journal of Experimental Psychology: Learning, Memory, and Cognition, 35, 780-805.

Soll, J. B., \& Mannes, A. E. (2011). Judgmental aggregation strategies depend on whether the self is involved. International Journal of Forecasting, 21, 81-102.

Szajna, B., \& Scamell, R. W. (1993). The effects of information system user expectations on their performance and perceptions. MIS Quarterly, 17, 493-516

Taleb, N. N. (2004). Fooled by randomness. Oakland, CA: Texere.

Tetlock, P. E., \& Gardner, D. (2015). Superforecasting: the art and science of prediction. London: Random House.

Tormala, Z. L., \& Clarkson, J. J. (2007). Assimilation and contrast in persuasion: The effects of source credibility in multiple message situations. Personality and Social Psychology Bulletin, 33, 559-571.

Tseng, S., \& Fogg, B. J. (1999). Credibility and computing technology. Communications of the ACM, 42, 39-44.

US EPA. (2009). Expert elicitation task force white paper. Washington, DC: Science and Technology Policy Council. http://www.epa.gov/osa/ pdfs/elicitation/Expert_Elicitation_White_Paper-January_06_2009. pdf (Accessed 7 July 2015).

Van Swol, L. M. (2011). Forecasting another's enjoyment versus giving the right answer: Trust, shared values, task effects, and confidence in improving the acceptance of advice. International Journal of Forecasting, 27, 103-120.

Van Swol, L. M., \& Sniezek, J. A. (2005). Factors affecting the acceptance of expert advice. British Journal of Social Psychology, 44, 443-461.

Venkatesh, V., \& Goyal, S. (2010). Expectation disconfirmation and technology adoption: polynomial modelling and response surface analysis. MIS Quarterly, 34(2), 281-303.

Wathern, C. N., \& Burknell, J. (2002). Believe it or not: Factors influencing credibility on the web. Journal of the American Society for Information Science and Technology, 53(2), 134-144.

Willemsen, L. M., Neijens, P. C., \& Bronner, F. (2012). The ironic effect of source identification on the perceived credibility of online product reviewers. Journal of Computer-Mediated Communication, 18, 16-31.

Woodside, A. G., \& Parrish, J. (1972). Positive disconfirmation of expectation and the effect of effort on evaluation. Proceedings of the Annual Convention of the American Psychological Association, 7(2), 743-744.

Wright, G., Bradfield, R., \& Cairns, G. (2013). Does the intuitive logics method-and its recent enhancements-produce effective scenarios? Technological Forecasting and Social Change, 80, 631-642.

Wright, G., \& Goodwin, P. (2009). Decision making and planning under low levels of predictability: enhancing the scenario method. International Journal of Forecasting, 25, 813-825.

Wright, G., \& Rowe, G. (2011). Group-based judgmental forecasting: An integration of extant knowledge and the development of priorities for a new research agenda. International Journal of Forecasting, 27, 1-13.

Xie, H., Miao, L., Kuo, P.-J., \& Lee, B.-Y. (2011). Consumers' responses to ambivalent online hotel reviews: The role of perceived source credibility and pre-decisional disposition. International Journal of Hospitality Management, 30, 178-183.

Yaniv, I. (2004). Receiving other people's advice: influence and benefit. Organizational Behavior and Human Decision Processes, 93, 1-13.

Yaniv, I., \& Kleinberger, E. (2000). Advice taking in decision making: egocentric discounting and reputation formation. Organizational Behavior and Human Decision Processes, 83(2), 260-281.

Dilek Önkal is Honorary Research Fellow at UCL and Professor of Decision Sciences at Bilkent University. Her research focuses on judgmental forecasting, judgment and decision making, forecasting/decision support systems, risk perception and risk communication, with a strong emphasis on multi-disciplinary interactions. Her work has appeared in journals such as Organizational Behavior and Human Decision Processes, Decision 
Sciences Journal, Risk Analysis, International Journal of Forecasting and the Journal of Behavioral Decision Making. She is an Editor of the International Journal of Forecasting.

M. Sinan Gönül is an Associate Professor in the Department of Business Administration at Middle East Technical University in Ankara. His research focuses on judgmental forecasting, judgment and decision making, and he has published in journals such as Decision Sciences, Journal of Forecasting Technological Forecasting and Social Change, and the Journal of Behavioral Decision Making.

Paul Goodwin is Emeritus Professor of Management Science at the University of Bath. His research interests are concerned with the role of management judgment in forecasting and decision making. He is a Fellow of the International Institute of Forecasters and co-author of Decision Analysis for Management Judgment (Wiley).
Mary Thomson is a Reader of Decision Science at Northumbria University. Her research interests focus on judgmental forecasting, forecasting support systems, risk perception and risk communication. Her work has appeared in several book chapters and journals such as Risk Analysis, Decision Support Systems, International Journal of Forecasting, and the European Journal of Operational Research.

Esra $\mathbf{0} \mathbf{z}$ is a Ph.D. candidate in Decision Science and Operations Management at Bilkent University. Prior to her Ph.D. studies, she received M.Sc. in Financial Engineering at Bogazici University and B.Sc. in Industrial Engineering at Middle East Technical University (METU). Since graduating from METU, she has been working as a project management professional at a leading company specializing in high level electric electronics systems. Her current research interests include scenario forecasting, judgment, and decision making. Mrs. Öz is a member of Project Management Institute (PMI) and Institute of Electrical and Electronics Engineers (IEEE). 